\title{
Perceptions of Residents in Xinjiang, Urumqi towards Tourism Development through China's Belt and Road Initiative
}

\author{
Grace Suk Ha Chan ${ }^{1}$, Irini Lai Fun Tang ${ }^{1} \&$ Mosa Wenxian Zhang ${ }^{1}$ \\ ${ }^{1}$ Faculty of International Tourism and Management, City University of Macau, Macau SAR, China \\ Correspondence: Irini Lai Fun Tang, Faculty of International Tourism and Management, City University of Macau, \\ Macau SAR, China.
}

Received: December 27, 2017 Accepted: February 1, 2018 Online Published: February 3, 2018

doi:10.5539/jms.v8n1p59 URL: https://doi.org/10.5539/jms.v8n1p59

\begin{abstract}
China's Belt and Road Initiative (BRI) clearly reads as an audacious vision for transforming the political and economic landscapes of Eurasia and Africa over the coming decades via a network of infrastructure partnerships across the energy, telecommunications, logistics, law, Information and Technology, transportation and tourism sectors. The BRI prioritises people-to-people connection. Various countries and cities will benefit from promoting cultural nationalism and local civic identities. The joint project of Belt and Road (B\&R) embraces the trend towards a multi-polar world, economic globalization and cultural diversity for upholding global free trade, allocating many resources and deeply integrating marketers. The BRI is a remarkable example of the borderless nature of infrastructure development. This initiative aims to foster economic growth and investment along the ancient Silk Road trading route between Europe and the East. For instance, in Xinjiang, Urumqi, various resources promoting the culture of the area add value to the tourism industry. This study adopted a descriptive research design that encompasses a qualitative approach and addressed the residents' perception and attitude towards tourism. In-depth interviews with residents were conducted. Recommendations were made for destination marketers and governmental practitioners on how to improve and facilitate tourism industry for Xinjiang, Urumqi.
\end{abstract}

Keywords: Xinjiang, Urumqi, residents, perceptions, tourism development, Belt and Road

\section{Introduction}

Belt and Road Initiative (BRI) is identified as the most significant and far-reaching initiative ever proposed by China. Five major goals, namely, policy coordination, facility connectivity, unimpeded trade, financial integration and people-to-people connection, are embedded within a broad framework of connectivity and cooperation (New Straits Times, 2017). In 2013, Xi Jinping unveiled the Silk Road Economic Belt and 21st Century Maritime Silk Road policy initiatives as significant elements of Beijing's current effort to improve ties and stimulate growth and development along its geographic periphery (Swaine, 2016). Xi Jinping delivered the concept of BRI at Nazarbayev University in 2013 as part of his visit to Kazakhastan. The BRI involves economic policies, which strengthen China's influence and align with various countries and cities along the Silk Road. The concept of BRI is to integrate cooperative and mutually beneficial sets of maritime and land-based corridors linking European and Asian Markets (Swaine, 2016).

The economic situation in China highlights and provides business and new development opportunities for countries eyeing foreign investments. Asian Development Bank (ADB) reported that Asia will require approximately 8.2 trillion USD (35.6 trillion RMB) to finance infrastructure development from 2010 to 2020 (Straits Times, 2017). This development accelerates the economic growth in Asia. Countries involved in the Belt and Road (B\&R) zone will multiply the markets and employment opportunities by expanding the scope for realizing infrastructure projects. China will become a platform to provide financing for infrastructure development, especially for investments under BRI (Xinhua, 2017).

According to $\mathrm{Wu}$ (2014), B\&R consists of several economic and non-economic elements. The most frequent feature is identified by economic value as well as the weight and variety of the infrastructure project to strengthen the economic capacity and connectivity among the nations involved in the B\&R. China attempts to utilize infrastructure development and connectivity construction to efficiently build the Silk Road Economic Belt and the 21 st Century Maritime Silk Road. 
BRI aims to promote connectivity among Asia, Europe and Africa and their adjacent seas and strengthen partnerships among the countries. The project will align and coordinate the development in these countries and capture the potential region; promote investment and consumption; create demand and job opportunities and enhance people-to-people, cultural exchanges and mutual learning among the citizens ( $\mathrm{Wu}, 2014)$.

From a geographic perspective, B\&R will be part of a new type of strategy designed to support a large effort enunciated by a new type of major country relations to achieve a win-win situation.

BRI aims to promote regional economic development, build friendship and long-term establishments among the countries along the Silk Road (Huang, 2016). BRI attempts to model the four foundation principles, namely, openness and cooperation, harmony and inclusiveness, market-based operation and mutual benefit for all the countries.

BRI geographically include three routes, that is, from China through Central Asia and Russia to Europe, from China through Central Asia and West Asia to the Persian Gulf and the Mediterranean and from China through Southeast Asia and South Asia to the Indian Ocean. The previous silk road runs from China's coastal ports through the South China Sea to the Indian Ocean, extending to Africa and Europe and from China's coastal ports through the South China Sea to the Pacific Ocean. The China-Pakistan and Bangladesh-China-India Myanmar economic corridors will work closely with B\&R economies (Xinhua, 2017).

The project is crucial to many countries, considering that several countries are constrained by inadequate financial support and planning and coordinating capabilities. According to the ADB's estimation, Asia's needs may reach 730 billion USD annually by 2020 . However, the ADB can only provide 10 billion USD. The B\&R should fill these gaps and generate additional finance for infrastructure. Such a project includes cross-border high-speed railroads, cross-border oil/gas pipelines and cross-border telecom and electricity links (ADB and ADB Institute, 2009).

A German scholar created the term "Silk Road" in the 19th century. The land route of the Silk Road stretched from China's Xi' an to the Mediterranean Sea for around 4000 miles $(6437 \mathrm{~km})$. The road was initially built during the Han Dynasty (206 BC-220 AD). In 138 BC, the Great Emperor Han Wudi sent imperial envoy Zhang Qian on a trade route across the border to the west. Camels and horses were used to transport silk from China, and the road was converted by Romans who considered a network of routes separated by major topological landmarks, such as the majestic Tianshan mountain range that stretches over $1500 \mathrm{~km}$ from China to Kazakhstan. Thus, the Middle route mentioned above basically follows the Northern Tianshan Route, whereas the Southern Route follows the Southern Tianshan Route (China Today, 2017).

\subsection{Benefits of the BRI}

According to BRI, it expects to have bought a large number of benefits, they include economic, transportation linkage, and cultural benefits from the following:

\subsubsection{Economic Benefit}

Mutual benefit is central to the role of the Silk Road economic belt, given that the deficiency in one country or region will be certainly supplemented by another. Central and West Asian countries are generally weak in the textile industry. For example, neighbouring Xinjiang has advantages in this field because of foreign investment and industrial reorganisation. In 2012, Xinjiang produced 28.26 million garments and 400,000 $\mathrm{m} 2$ of carpets (Xinhua, 2017).

\subsubsection{Transportation Benefits of Transportation Links}

An international train line opened at the end of 2013, linking China and Europe. Starting in Xi'an, the railroad passes through Xinjiang and Central Asia and is expected to stimulate the development of railway logistics along the route. China has invested in many large projects in Central Asian countries requiring efficient transportation of numerous materials and facilities. Conversely, countries in Central and West Asia are increasing their investment in Western China. As a result, transport of goods has become a priority requiring immediate action. Building a Silk Road economic belt aims to optimize regional trade and production factors via transportation infrastructure in key cities along the Silk Road. Such activities are expected to promote regional economic integration. Consequently, a sound transportation network that can facilitate regional trade and investment among East, West and South Asia is a must for the viability and prosperity of this economic belt (Global Times, 2015). Development should include upgrading tourism facilities, such as building new villages for minority groups, upgrading tourist destinations and installing a high-speed rail system. The spectrum of new projects is impressive. Construction upgrade and construction of Urumqi's transport system are expected to affect the capital and the province the most. With the expected completion in 2018, Urumqi's metro rail will link different parts of the city. The high-speed train system 
that will run for $15 \mathrm{~km}$ outside the city will link other Chinese cities (Global Times, 2015).

\subsubsection{Cultural Exchange}

One of the lessons of the original Silk Road is that cross-border trade and cultural exchange build mutual respect and trust. Transforming affordable tourism and transport hubs with wealth generation will integrate the communities around the B\&R. As cross-border and domestic tourism brings business opportunities to these regions, the Han Chinese migrating to the area will also be increased eventually. For the Chinese in Central Asia, the spectre of Islamic fundamentalism demands policies that transform long and, in many cases, porous borders from a threat to an opportunity for creating the types of social stability originating from economic prosperity.

\subsection{Xinjiang Uyghur Autonomous Region (XUAR)}

Five Central Asian nations, namely, Kazakhstan in the north bordering Russia, and to its south, Turkmenistan, Uzbekistan, Tajikistan and Kyrgyzstan, are all destined to benefit from China's BRI and can become an economic hub within Eurasia. Three of the five share a border with China, and China has laid railroads through its vast western province, Xinjiang, to these borders with Kazakhstan, Kyrgyzstan and Tajikistan, where dry ports are set up along these borders (Rayila, 2011). Xinjiang consists of the unique geological advantages in economic cooperation and cultural exchange; thus, considering how to change the potential superiority of resources into superiority of economics is the power and purpose of developing Xinjiang's tourism.

XUAR is located in the north west of China and shares borders with eight countries, namely, Mongolia, Russia, five Eurasian countries (Kazakhstan, Uzbekistan, Tajikistan, Kyrgyzstan and Turkmenistan) and Pakistan. The area once served as a hub along the ancient Silk Road and Europe. The Turkic people are distributed mainly in Central Asia, and Turkic language belongs to the Altay-Turkic language family. The population of Turkic people is nearly 170 million, and the largest population of Turkic people are the Turkish group accounting for nearly 70 million. Among the Uyghur population in Xinjiang, China ranks fourth. China, Russia, Iran and Turkey are the four major countries that play an important role in Central Asian geopolitics (Rayila, 2011).

Central Asia's Turkic majorities play a crucial role in the success of China's BRI. The importance of the Silk Road to Xinjiang is equally noteworthy. Xinjiang is the residential region of Turkic peoples, including Turks, Azerbaijanis, Kazakhs, Uzbeks, Kyrgyzs and Uyghurs, who comprise the largest ethnic groups in the Central Asian Region. In China's northwestern province of Xinjiang, Uyghurs, a Turkic-Muslim ethnic group native to Xinjiang, comprise nearly 50 percent of the population. Sub-regional economic cooperation is a form of regional economic integration to strengthen the development of regional economic integration. Pushing forward sub-regional cooperation can bring enhanced geographical advantages into play and boost regional development. The BRI is the essence of cross-border sub-regional cooperation. From a regional economic development perspective, the policy focuses on Xinjiang and other western regions is conducive to enhancing the vitality of the central and western regions for promoting regional economic development. With tourism a highly associated and open new industry, an increasing number of regions maximize area advantages, break district and push on regional tourism cooperation for their own economic profit (Economic and Information Commission of Xinjiang, 2012). China's restive western frontier region, Xinjiang, is home to a large number of Turkic Muslims, a majority of which are Uyghurs. Although known as XUAR, several autonomous prefectures and counties can be found within its borders, where other minority groups converge.

With a population of 23 million, China's largest administrative division has approximately 50 minority groups, and 13 main ones, with Muslim Uyghurs and the Kazakhs as the two largest. Communist China established the autonomous region in 1955 and began encouraging the Han Chinese to settle in the new industrial towns and farming villages run by the quasi-military Xinjiang Production and Development Corps. In the 2000 Census, Han Chinese comprised $40 \%$ of the population of Xinjiang, excluding large numbers of troops stationed in the region and unknown numbers of unregistered migrants, and Uyghur accounted for approximately 45\% (Xinhua, 2017).

Considering the above facts, we can predict that $B \& R$ can connect to the world because of the investment from outsiders and infrastructure construction will be improved. Therefore, examining the local residents' perception towards Xinjiang development is worthwhile.

\subsection{Problem Statement}

\subsubsection{Conflict between Religion and Culture}

Xinjiang is a multi-ethnic centre with majority of people believing in Islam. According to data information, ethnic minorities accounted for $59.87 \%$ with respect to the total population of $21,813,300$ in Xinjiang as of 2010 (Xinjiang Census, 2010). XUAR has 24,800 venues for religious activities, around 24,400 of which are Muslim mosques. Among the major religions in Xinjiang, Islam has the most followers. A total of 13 million people from 
10 ethnic groups, such as Uyghur, Hui, Kazakh and Tajik, believe in Islam. The Muslim population of Xinjiang is approximately 13 million and constitutes over half of China's total Muslim population (Beijing Review, 2016). In recent years, local terrorist attacks have slowly increased as influenced by extremist religious forces. Despite such developments, these groups have moved towards the right direction of avoiding religious extremism by promoting Islamic education as a matter of national security.

\subsubsection{Discrepancy across Individual Income}

The major ethnic group of Uyghurs face serious discrimination in the job market, as stated by Prof. Wu Xiaogang from the Social Science and Technology Department (Hua, 2015). Nearly 80 percent of Uyghurs still farm and can be found largely in the poor southern half of Xinjiang. One focus of the top-level party meeting lay on the following concern: inequality and unemployment rate among young Uyghurs in the south were fanning unrest. The senior officials in attendance decided to offer low tax rates and other benefits to companies that bring jobs to southern Xinjiang. The officials pledged that at least one member of every Uyghur family will have a job; however, under this policy, they earned less than the Han Chinese with annual payouts, their income was only as high as 10,000 yuan for five years (Hua, 2015).

These problems exist in Xinjiang, and when BRI is implemented, the conflict and problems may be difficult to solve. Therefore, identifying the local residents' perception towards Xinjiang development is worthwhile to provide policy advice to a developing country government. Research will focus on Urumqi, one of the largest cities in Xinjiang. With emphasis on infrastructure for economic development, and tourism development, ways of solution to be included into its execution. Value supplement resources support should be provided to the existing international system. The implicit belief of BRI is the best policies and different stages of development that also deserve consideration when reforming the existing system.

\subsection{Significance of the Study}

Rural tourism in China developed in 1970, and such a development led to increased number of cities generating local economic and social multiplier effects (Guo \& Sun, 2016). Many studies in China identify the problem in China, and their analysis follows various forms from precondition and proposition of solution to development problems (Tan, 2009). These studies are viewed from the governmental standpoint. However, limited research investigates the $\mathrm{B} \& \mathrm{R}$ in relation to their effect on the rural area; a lack of discussion is observed regarding how the residents view the future development of their communities. This study is the first attempt to investigate the Xinjiang residents' viewpoints about the effect of B\&R on tourism development. Study will base on material, community, health and safety issues bought from B\&R for further discussion.

This study aims to investigate the views of the residents from the rural and urban areas, especially regarding their perceptions and attitudes towards the tourism development under the BRI. To obtain authentic material, we adopt the interview approach and inquire locals regarding their perceptions on the tourism development. The information covers both advantages and disadvantages from the locals' perspective.

To gather the residents' knowledge on the B\&R policy from the government and its implications on their lives, feedback from the public must be obtained. Analysis of the reasonableness and feasibility of the policy must also be conducted.

Assisting the relevant government departments in gaining a comprehensive understanding of the social conditions and public opinions are required consideration of the transpositional job. Previous studies scarcely discuss B\&R (Swaine, 2015; Huang, 2016), although the new initiatives have led to different issues. The present study is the first attempt to investigate the attitude of local residents towards tourism development in Xinjiang. The study results will benefit the local community and Chinese tourism. Although a few scholars have identified the rural residents' attitude towards tourism development issues, they tend to focus on the effect and holistic approach (Allen et al., 1993; Nunkoo, 2016; Ali Hasani, 2016). Little study covering this new topic discusses in the context of Xinjiang area, hence information and or problems related to the cities are also limited. Notably, the B\&R project significantly affects the locals, including community and tourism development. As the results will provide recommendation to developers and marketing leaders, developing B\&R must still consider the effect on the local residents.

This study investigates from another direction. The study proposes that perception of residents towards tourism influences with their sense of well-being in four domains, namely, material, community, health and safety. The sense of well-being of residents in these life domains affect their overall life satisfaction.

This research aims to achieve the following objectives:

1) examine the residents' attitude towards tourism development of $B \& R$ in Xinjiang; 
2) identify the perception of residents with the effects of tourism from B\&R in their life and community;

3) offer the government recommendations for future destination improvement.

\section{Literature Review}

\subsection{Tourism as Generator of Wealth in Xinjiang}

Rural tourism represents a key component in the socio-economic development in the region (Burns \& Novelli, 2008). In view of the Tourism industry can help to well distribute the income gained from tourists for the rural population, so as to guarantee a prosperous development of the region. Tourism activities that can generate income and distribute this income among the society. Tourism is carried out with periodicity, without the typical seasonal nature given by the area. Creating employment no longer has to be temporary and serves as the majority of seasonality. Moreover, the negative sides will exert undesirable effects in the areas. To illustrate, long-term cost of living will increase, however, the agricultural areas will decrease. All these factors will secure effective planning, and running of all the regional resources will be necessary to ensure that tourist destinations are overloaded with visitors; otherwise, they will lose all their authenticity and charm. In the implementation of BRI, perceptions are considered as the rationale of the study that can assist in understanding how the local residents perceive Xinjiang tourism development after BRI is implemented in China. Many studies explore residents' perception towards tourism development, and these studies likely relate to the negative and positive effects (Andereck et al., 2005; Ap, 1992; Uysal \& Sirgy, 2012). Limited studies examine how residents in Xinjiang relate to the development through $\mathrm{B} \& \mathrm{R}$. The present study aims to fill this gap and provide value to industry practitioners and local authorities in terms of relevant management.

\subsection{Residents' Perceptions towards Tourism and Theory}

Residents' attitude and perceptions are crucial because local residents are affected by tourism-related activities, and the local people tend to have more concerns with tourism that might have led to the environment decay. Content and consulted residents tend to support local pro-tourism initiatives and display hospitality towards tourists. Conversely, dissatisfied visitors are discouraged by repeating visit intentions due to word-of-mouth recommendations (Ap, 1992; Morrison, 2009). Fredline \& Faulkner (2000) mentioned such clustering as evidence of social representations theory or the tendency to make sense of the revealed world through a system of reference and meaning shared among different groups of individuals and shaped by a "dynamic process of interaction and communication" (Zhou \& Ap, 2009, p. 79). The development of local tourism industries and infrastructure and subsequent interactions with tourists exert direct effects on communities (Sharpley, 2014). According to Andriotis \& Vaughan (2003), positive attitudes towards tourism development among urban residents in Crete are influenced by exposure to the tourism industry through employment.

Allen et al. (1993) explored residents' attitude towards tourism development in communities with both high and low economic and tourism development and identified with which residents have more positive attitudes. Other studies find that negative social representations of environmental impacts from tourism are by large as a result of rumour spreading and personal exposure (Yuksel, Bramwell, \& Yuksel, 1999). Negative effects relate to an increased cost of living (Liu \& Var, 1986) due to the rising price of properties, goods and other products. Other scholars consider that negative impact is associated with the environmental viewpoint, including damage to the natural environment and ecosystems. Examples are air, water and other environmental pollutants (Ko \& Stewart, 2002). Many studies associate tourism employment with positive attitudes because employees may obtain more personal benefits than the cost (Korca, 1998; Madrigal, 1995). McGehee \& Andereck (2004) mentioned that local residents of tourism-dependent destinations are more aware of the negative impacts than the positive ones.

Previous studies discuss the resident-visitor relations through social exchange theory (SET) (Emerson, 1976). SET refers to a two-sided rewarding process involving two or more social groups (Boley et al., 2014). The theory applied to the field of tourism that explains the perceptions of host community residents towards tourism development (Haobin Ye et al., 2014; Jurowski et al., 1997). The theory aims mainly to discuss the cost and benefits of tourism development. Ap (1992, p. 669) discussed SET as “...understanding the exchange of resources between individuals and groups in an interaction..."

SET is a social, psychological and sociological perspective explaining social change and stability as a process of negotiated exchanges between parties. This theory posits that human relationships are formed using a subjective cost-benefit analysis and comparison of alternatives. The theory has roots in economics, psychology and sociology. SET features many of the main assumptions found in rational choice theory and structuralism. The rationale of the theory lies on how residents believe that the benefits and advantages of tourism development exceed the cost of development, and thus the residents are inclined to support tourism development (Jurowski et al., 1997). 
Liu \& Var (1986) found that although residents are more concerned about protecting their environment than considering economic gains, they are also keen on improving the standards of living over environmental concern. Previous scholars identified SET's focus on interpersonal exchange to six rules, namely, reciprocity, rationality, altruism, group gain, status consistency and competition (Cropanzano \& Mitchell, 2005). Conversely, Weber's theory of rationality is considered to explain how the factors interact with residents' value and belief to influence their perceptions (Rasoolimanesh, 2015). Most of the group gain benefits accrued by the community rather than individuals, and, in turn, individuals derive benefit from the group. By all means, positive effects may not directly benefit their perception of these effects (Cropanzano \& Mitchell, 2005). Woosnam et al. (2009) conducted a research to develop the constructs of theory of emotional solidarity in reference to Durkheim (1995) and investigated the relationship between destination residents and tourist residents and tourists' emotional solidarity. Therefore, local development should have a correlational link to local residents' emotional solidarity.

\subsubsection{Welcoming Nature}

Woosnam (2009) argued that "welcoming nature" implies the local residents' "personal interests in tourists and tourism". Woosnam (2009) justified that a welcoming nature towards tourists significantly predicts residents' level of support for tourism development. Residents possessing a welcoming nature towards tourists have a personal interest in tourism development and duly benefited from it. Thus, these residents have a positive attitude and will support tourism development within their respective communities. Woosnam (2009) also deduced that residents tend to have a significantly higher degree of welcoming nature compared with tourists because residents regard the place as their "home turf" and see themselves as hosts.

Residents' level of welcoming nature towards tourists will have a positive effect on their attitude towards tourism development.

\subsubsection{Emotional Closeness}

Emotional closeness is an important aspect of interpersonal interactions and relationships. We define emotional closeness as the degree to which individuals perceive others to have caring feelings for them and to be physically and verbally affectionate as well as emotionally supportive.

Importantly, the degree to which a person responds to emotionally close behaviours (e.g., handholding), which is probably moderated by "how much a person desires emotional closeness", may be important in understanding the psychological outcomes of social interactions. However, Woosnam (2012) discovered that emotional closeness with tourists does not directly predict residents' level of support for tourism development. He further mentioned that emotional closeness strongly predicts the contributions that the tourism industry provides to its community (Woosnam, 2012). Such friendships are a paramount example of the social effects reaped via tourism in a destination.

Residents' level of emotional closeness towards tourists will have a positive effect on their attitude towards tourism development (Figure 1).

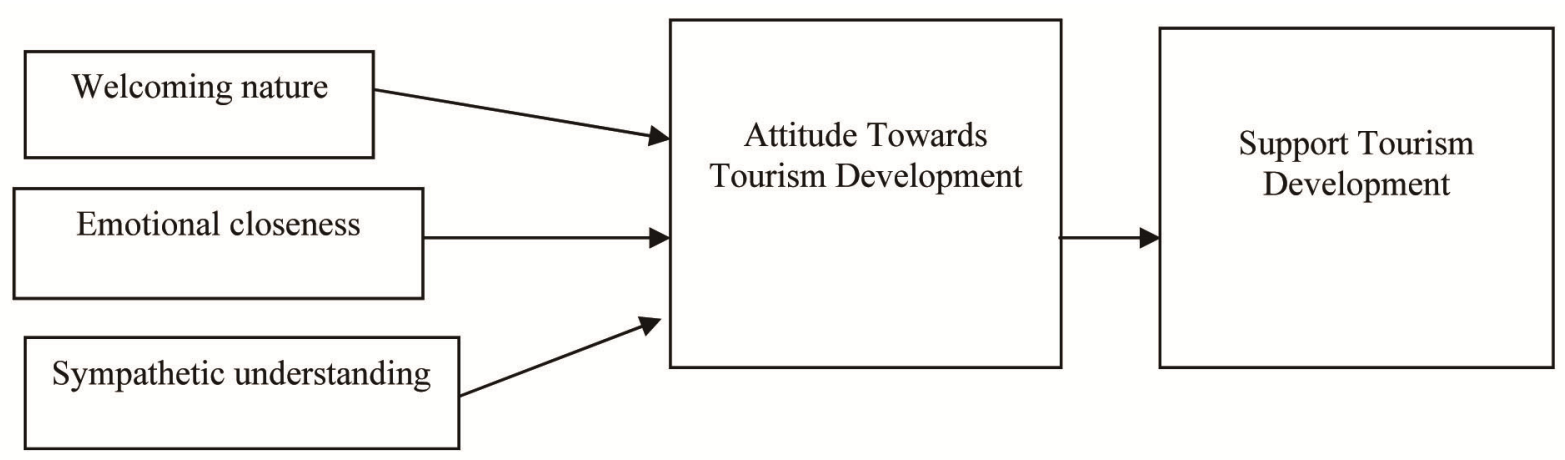

Figure 1. Factors affecting the attitude towards tourism development

Source: Ali Hasani, Sedighen Moghavvemi \& Amran Hamzah, 2016.

\subsubsection{Sympathetic Understanding}

Sympathetic understanding towards tourists significantly predicted from the residents' level of support for tourism development. If residents have high levels of sympathetic understanding towards tourists, then they are assumed to 
display a positive and supportive attitude towards tourism development. Moreover, sympathetic understanding strongly influences attitude. Principally, if these people reside in a tourist destination area, then they will be able to interpret and apprehend the feelings of residents and tourists. Many residents and tourists posited that they experienced a positive degree of sympathetic understanding with one another because residents are accustomed to tourists utilizing amenities at their destinations (Draper \& Woosnam, 2012). This type of empathy shown by residents grants them the opportunity to "put themselves in others' shoes", as far as the negative social effects of tourism in their community are concerned (Kohn, 1997).

Residents' level of sympathetic understanding towards tourists will have a positive effect on their attitude towards tourism development. Intuitively, positive attitudes among residents are one indication that tourism development is appropriate for local conditions. The theoretical significance of understanding any possible resident's attitude is based on the relationship between attitude and behaviour.

\subsection{Reason behind Residents' Perceptions}

The reason leading to the residents' perception is identified in many studies (Gursoy et al., 2002; Choi \& Sirakaya, 2006; Wang \& Pfister, 2008; Nicholas et al., 2009). In our study, we investigate the local residents of Xinjiang, particularly the influences affecting the development of residents' perception towards tourism development through B\&R. Studies highlight the community attachment concerns, such as feelings, emotions and sense of belonging of local people (Nicholas et al., 2009). Even a few scholars deemed community attachment as a function of the residents' length of residency and sense of belonging. McCool \& Martin (1994) and Rasoolimanesh et al. (2016) claimed that the residents are concerned of the benefits and cost of tourism development for their development not for themselves. Residents who are attached to their communities want to see their community develop, but they are also worried of the negative effect of tourism on their community.

Sutton (1967) argued that the encounter between the host community and the guest may provide either great opportunity to reward and satisfy exchanges or it may stimulate and reinforce the impulse to exploit on the part of the host. Supporting this assertion, many studies reveal that economic, social and environmental elements resulting from the host-tourism exchange process affect residents' perception of tourism. Many discussions occur during the exchange process with the local community, not only on economic components but also on the socio-cultural and environmental factors.

\subsection{Residents' Attitudes towards Tourism Development}

Many studies demonstrate the residents' attitudes affecting tourist satisfaction and return intention. Some locals welcome tourists with open arms, whereas others view tourists with ambivalence (Ali Hasani et al., 2016). In addition, residents gearing towards tourism evolution can be explained in the context of socioeconomic, socio-demographics and travel behaviour variables (Woosnam, 2012). When locals depend on the tourism industry, they would show willingness to support the latter. Therefore, residents' show of support will influence the tourism activities and businesses. The resort area of distribution around Xinjiang is generally located in the suburbs or outskirts of the city. Tourism has improved agricultural markets in two ways. First, demand from residents has increased, considering that some are now fully employed in tourism and can no longer grow their own food or raise cattle. Such residents spend a portion of their tourism earnings on food-multiplying tourism revenue throughout the community (Simmons, 1994). Moreover, the neighbouring country, Kazakhstan, has opened the group visa to Chinese citizens on July 15, 2016, enabling Xinjiang to evolve into the most important transfer hub in China. An increasing number of people wish to travel abroad in recent years, thereby creating an opportunity to develop and strengthen the tourism infrastructure construction. Tourism development may also affect a person's perception of social ranks (Jiang, 2015).

\section{Methodology}

This study adopted qualitative approach to collect evidence from local residents regarding their perceptions towards the development brought by $\mathrm{B} \& \mathrm{R}$. A descriptive research design was adopted using a qualitative approach to investigate tourism development in Xinjiang. Descriptive research designs collect evidence to assist the researchers in understanding the local residents' attitudes towards tourism development. Such designs are generally the best method for collecting information that can demonstrate relationships between the local residents and the tourism industry. This study employed the descriptive design to determine the feasibility of implementing investigations among local residents. This study adopts the interview approach to understand the emotional changes among local residents.

Local residents in the rural and urban areas in Xinjiang were interviewed regarding their perception of the tourism development in the area and its effects after the development of local tourism. The interviewees were provided 
with study facts in advance (both in English and Chinese) to gain understanding of the research objectives.

In addition, the researcher gained familiarity with local government's policies. The main research key questions are as follows:

(1) What is your perception of the effects of B\&R in Xinjiang?

(2) How do you feel about this change?

(3) Do you think B\&R can benefit your life and community?

(4) Can you make any recommendations to the government for future destination development?

Interviewees were asked how they perceived the local tourism development on the benefits after the implementation of the BRI. Suggestions were also sought from them on creating a reasonable sustainable development tourism plan.

The purposive sampling is adopted in this study. This type of sampling technique is appropriate if the population to be studied is difficult to locate, or if some members are thought to be more appropriate (knowledgeable, experienced, etc.) for the study than others (Nawijin, 2011). The research questions were based on their perception of the effect of B\&R. They were asked regarding the changes as well, the understanding of the benefit and recommendation for future destination developments. Audio recordings of interviews were transcribed into traditional Chinese and then translated into English. Conducting the entire interview process required the use of Mandarin to communicate with local residents. Bilingual versions of the questions in English and traditional Chinese were produced.

Respondent selection was based on the following criteria. They are local residents in Xinjiang (including urban and rural residents in Xinjiang) and should have heard of the B\&R project. For easy location of the respondents, interviewers conducted the research in one of the largest and popular shopping malls and subsequently conducted an in-depth interview using self-administered questionnaires.

In the audio recordings of the interviews, conducting the entire interview process required the use of Mandarin to communicate with local residents. Each interview lasted for 40 minutes. Interviews took place in one of the small café and restaurants in one of the popular shopping malls.

Miles \& Huberman (1994) pointed out that qualitative data tend to be collected in word form based on interviews and documents. In this study, in-depth interviews and various secondary data sources (i.e., title of company, brochures, flyers, journals and industry reports) were used. The public opinion survey report of the investigation had become the main sources of secondary data. Other sources originate from the separate non-probability sampling of 25 Xinjiang local residents from rural and urban areas, generally seeking to understand the effects of the details on local residents.

The data were summarized and organized following the themes generated by the documentary review. The summaries of the interviews were prepared as well to emphasize the emerging main concepts and to set the context for the quotes to be selected and used as examples in the research report. Data analysis and coding were conducted in several stages. The generated codes were categorized and displayed in themed charts. Domain analysis was used for separate description and analysis of each theme. The coding results at different levels were compared to explore differences in opinions and suggestions. The findings at different levels were synthesized thereafter, and the coding results were compared to explore variances in opinions and suggestions. The resulting explanations and discussions were compared vis-à-vis the results of previous research.

\section{Results and Discussion}

The interviews were conducted in two weeks (January 15 to 30, 2017). The details of the profiles of the respondents can be seen in Table 1. Among the 25 respondents, half of the respondents were female, and the age group of the respondents ranged from 20 to 60 accounting to $60 \%$. In terms of educational level, $53.3 \%$ of the respondents obtained a certificate, diploma or higher diploma. Most respondents had incomes ranging from USD350.00 to USD1500.00.

Interviews took place in public spaces, such as a restaurant or coffee shop. The comfortable environment could stimulate the respondents to display openness in addressing the questions. 
Table 1. Profile of the respondents

\begin{tabular}{|c|c|c|}
\hline Characteristics & Frequency & Percentage \\
\hline \multicolumn{3}{|l|}{ Gender } \\
\hline Female & 14 & $56 \%$ \\
\hline Male & 11 & $44 \%$ \\
\hline \multicolumn{3}{|l|}{ Age } \\
\hline 18 to 25 & 0 & \\
\hline 26 to 33 & 8 & $32 \%$ \\
\hline 34 to 41 & 5 & $20 \%$ \\
\hline 42 to 49 & 6 & $24 \%$ \\
\hline 50 to 57 & 4 & $16 \%$ \\
\hline 58 to 65 & 2 & $8 \%$ \\
\hline 66 and above & 0 & \\
\hline \multicolumn{3}{|l|}{ Level of Education } \\
\hline Elementary & 10 & $40 \%$ \\
\hline Junior secondary & 6 & $24 \%$ \\
\hline High school & 4 & $16 \%$ \\
\hline Certificate, diploma or higher diploma & 3 & $12 \%$ \\
\hline Master's degree and above & 2 & $8 \%$ \\
\hline \multicolumn{3}{|l|}{ Income level } \\
\hline \multicolumn{3}{|l|}{$100 \mathrm{USD}=688 \mathrm{CNY}$ Monthly } \\
\hline $350-500$ USD & 3 & $12 \%$ \\
\hline 500-600 USD & 4 & $16 \%$ \\
\hline 600-700 USD & 4 & $16 \%$ \\
\hline 700-800 USD & 1 & $4 \%$ \\
\hline 800-1000 USD & 2 & $8 \%$ \\
\hline 1000-1500 USD & 1 & $4 \%$ \\
\hline \multicolumn{3}{|l|}{ Length of stay } \\
\hline $1-3$ years & 1 & $4 \%$ \\
\hline $3-5$ years & 1 & $4 \%$ \\
\hline $5-20$ years & $\mathrm{n} / \mathrm{a}$ & $\mathrm{n} / \mathrm{a}$ \\
\hline Over 20 years & $\mathrm{n} / \mathrm{a}$ & $\mathrm{n} / \mathrm{a}$ \\
\hline Permanent resident & 23 & $92 \%$ \\
\hline \multicolumn{3}{|l|}{ Occupation } \\
\hline Farmer or herdsman & 8 & $32 \%$ \\
\hline Educational institution employee & 1 & $4 \%$ \\
\hline Medical staff member & 1 & $4 \%$ \\
\hline Recreation serviceman & 7 & $28 \%$ \\
\hline Businessman (entrepreneur) & 8 & $32 \%$ \\
\hline
\end{tabular}

With the level of the urban-rural gap continuing to widen in recent years, the interviewees were separated into two divisions: the urban samples or the residents in the urban area and the rural samples or the residents in the country area.

\subsection{Local Residents' Expectations towards Tourism Development in Xinjiang}

\subsubsection{Material Aspect from Local Residents}

Nearly 90 percent of the interviewees are permanent local residents. Those interviewees living in the rural and poor area are expected to improve their living standard and environment. They believe that the infrastructure construction will facilitate the exchange of people and communication. Residents wish to enhance their household incomes and obtain other employment opportunities.

Most of the interviewees expected Xinjiang to develop into other innovative products in tourism industry. They prefer to have better sufficiency in the recreation tourism products and programs. They understood that the region requires large investments to develop in tourism. Therefore, combining itself with the unique natural resources and sustainable cultural elements can attract tourists to visit Xinjiang, thereby possibly benefitting the tourism business and increasing tourist expenditures. Xinjiang's value is explicit on its beautiful view. Locals realized their possible significant contributions to tourism and the dependence of significant progress on the desire partake from both governments and civil society to create the right setting for the future.

Most of the interviewees living in the rural area expect that they can upgrade their social life and gear towards a 
modern life. They can narrow down the economic gap compared with the other cities. Most interviewees foresee that Xinjiang will be recognized as a hub after the Implementation of B\&R. Consequently, B\&R can connect the eastern and western parts to attract other tourists, thereby possibly creating other jobs and other opportunities for local businesses. In the long run, the B\&R implementation can benefit the social and economic developments.

Opening the tourist market in Xinjiang can assist the region in enhancing the service quality while simultaneously providing other tourism professionals and management. Thus far, the largest tourism market is based on Muslim tour groups; this market phenomenon will expect further diversification in the tourism resources.

4.2 Identify the Perception of Residents Regarding the Effects of Tourism brought by $B \& R$ in their Lives and Communities

\subsubsection{Community Aspects from Local Residents}

Most interviewees believed that the effect of B\&R project will provide quality and quantity of infrastructure input. The project can have a direct effect on the regional development. They consider Urumqi as a well-known city; thus, growth of the infrastructure will provide support in the local community. As the government pushed ahead with the $\mathrm{BRI}$, they worked to increase complementarities between the development strategies and practical cooperation between China and other countries along the routes.

The road system will be regulated, and a large demand for equipment and logistical issues will be necessary. Local residents believes after B\&R project launch, the community will attract a large number of various experts to work in Xinjiang. Moreover, a multi-workforce will attract the talents from other places in the world.

Interviewees claimed that $\mathrm{B} \& \mathrm{R}$ can influence the utilization of customer markets, including other visitors from the Central Asia Region, such as Kazakhstan, Kyrgyz Republic, Tajikistan and Uzbekistan. This expected influence can benefit both inbound and outbound tourism businesses. From the cultural aspect, many locals who live in Xinjiang would like to share their custom and culture to the visitors, as a result it can enhance the destination image in order to promoting tourism in Xinjiang. Interviewees believed that through the BRI and subsequent vigorous development of agricultural tourism, agricultural tourism not only increased their incomes but also promoted rural economic prosperity. Alternately, some individual businesses may influence the necessity for cultural industry, such as Kazakh dancing and dressing up. Diversity in culture will largely affect Xinjiang after $\mathrm{B} \& \mathrm{R}$ implementation.

\subsubsection{Health and Safety Issues}

Some of the interviewees employed in a tourism resort tend to expect the booming of the businesses, whereas others were worried about the possible cultural conflicts between the Xinjiang locals and the Han Chinese visitors. The latter tend to have apprehensions regarding other immigrants, such as the Han Chinese to Xinjiang seizing their resources away for the benefit of those people. They tend to fear the possible crime rates increase as a result. One of the interviewees expressed concern regarding the government possibly taking over their farm lands, which will consequently deprive them of their household incomes. Their limited primary educational backgrounds added to this anxiety.

Some of the local interviewees have high expectations in the transportation link after the B\&R project launch. They hope that Xinjiang can be developed into a distribution centre for transporting goods and trade with Central Asia and China. Consequently, an increasing number of entrepreneurs from the mainland have expressed preference to relocate in Xinjiang. However, the negative result after establishing the transporting hub includes the continuing expansion of urban areas. Thus, their human inhabitants shall contribute to all sorts of pollution, such as air pollution, light pollution and even noise pollution. The urbanization will lead to pollution problems. Overusing the fragile natural environment via tourism would finally result in a terrible problem of ecological disruption in Xinjiang. (See figures 2) 


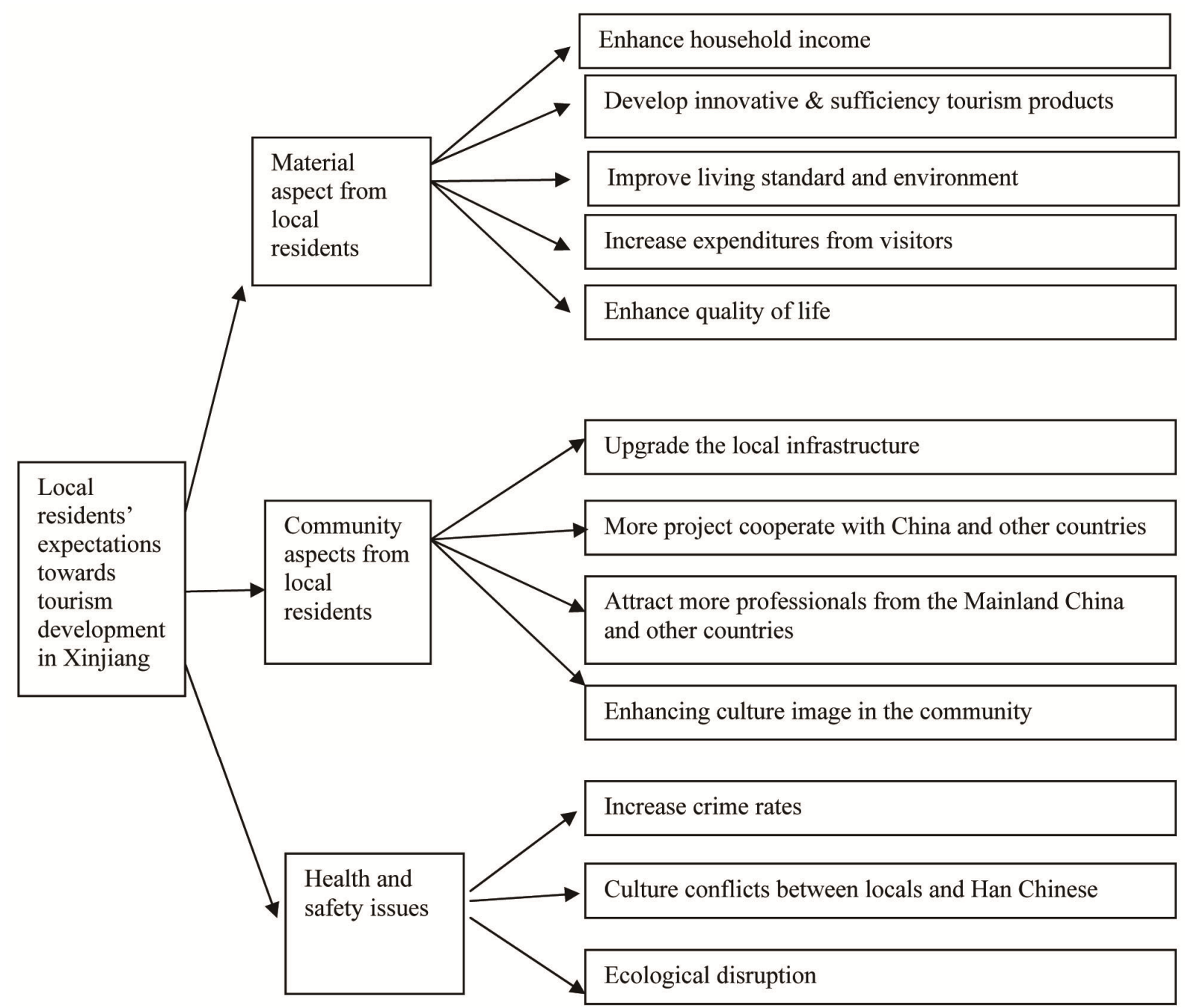

Figure 2. Local residents expectations towards tourism development in Xinjiang

\subsection{Recommendations to the Government for Future Destination Improvement}

Although nearly most people agree that tourism planning is necessary in Xinjiang, some of the interviewees recommended the provision of tourism planning and management for coexistence with local cultural inheritance and the necessity to raise public awareness of the need to protect minority cultures and guarantee the group's rights. These efforts will provide further support for the local tourism development. With regard to the development for tourism business in Xinjiang, interviewees prefer less changes in their environment, such as degraded resources. Interviewees mentioned of the demand and supply sides possibly balanced within the maintenance of social and environmental objectives. Some interviewees suggest that the government should support small and medium-sized company to promote rural economic prosperity.

Some interviewees mentioned the use of Tianshan piedmont as an example. The Tianshan area is the county landscape and is an ecological area with low mountains, hills, forests and grasslands. This area is a transition zone; moreover, water conservation and groundwater recharging are important elements of the place. Energy saving could also be an important measure that could contribute to control air pollution. With the increasing population of visitors coming to Xinjiang, problems are expected, such as overloading of scenic spots. Therefore, the government should provide sustainability planning and environmental protection. Despite the importance of economic benefits, locals are concerned about the threat to the living environment because of this development. They also highlighted that the government should recognize that all development sectors and support facilities and services are interrelated with the natural environment and society of the area.

\section{Conclusion}

As a crucial region in the BRI, Xinjiang assumes the role as the bridgehead of cultural exchange and economic 
interaction. This study focuses and examines the perceptions and attitudes of interviewees and subsequently raises suggestions for future tourism planning and development. Tourism must be advanced in consonance with the principles of fairness and equitable distribution and should balance development with the conservation of resources.

The results of this study provide further understanding in relation to the local residents' comments on BRI. This research gathers interesting findings from the residents in both the urban and in rural areas, thereby providing different perceptive values on the $\mathrm{B} \& \mathrm{R}$ project.

Residents valued less the effects of tourism development on community found in the samplings of those living in the rural area. The residents living in the rural community displayed a positive attitude towards tourism development; they wish they can engage in or ultimately benefit from tourism business. They considered the community a priority as a place for earning and living. Conversely, they deem the initiative to provide possibly positive destination image with progressive infrastructure advancement in order to ensure leading to quality of life. As economic activities increase, residents will create satisfaction and positive support in relation to tourism development. For rural communities, people with extremely low level of tourism development, low economic activities appear for those communities were living high tourism development with high economic activities show more enthusiasm towards tourism development. Consequently, they manifest positive attitudes in supporting the development due to their behaviours. High tourism development with high economic activities will express high support in the B\&R development found in the rural communities.

Conversely, residents living in the cities who bought houses and enjoying beautiful scenery are those who are concerned with the visitors intruding their daily lives and creating congestion in the traffic. They tend to express less support for tourism development. Residents concerned with the place where they live and earn a living manifest care for the environment, activities, sense of belonging and sensitivity to the B\&R tourism development. They intend to focus further on environmental protection and holding capacity. Consequently, they have negative attitudes on tourism development. High economic activities and low tourism development are basically economically stable, and thus the urban residents do not see the urgent need for tourism development (see Figure $3)$.

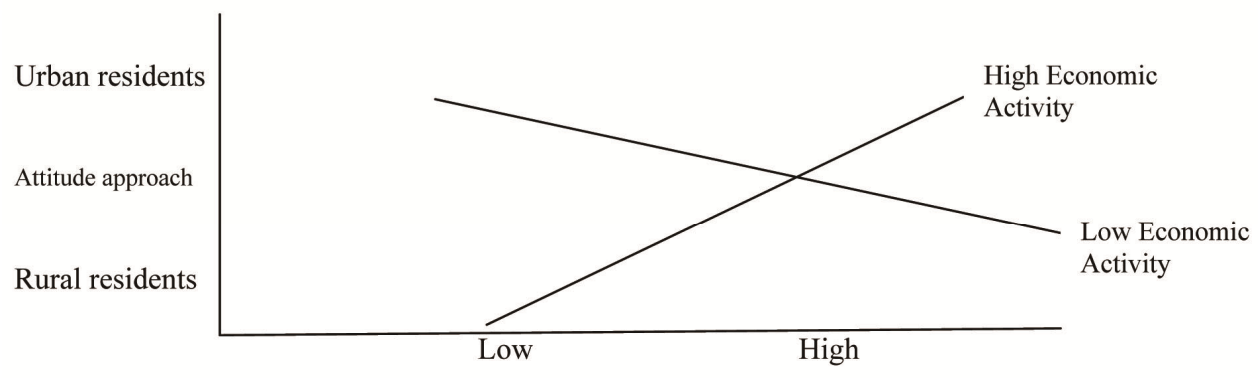

Agreement with Level of Tourism Development

Figure 3. Result of the attitude approach of urban and rural residents regarding their perception towards tourism development

Table 2. Different perspectives from rural and urban residents toward $B \& R$

\begin{tabular}{lll}
\hline Different perspectives towards B\&R & \\
\hline & Rural residents & Urban residents \\
Financial & Income gain & Various economic benefits, trade business, connection \\
Human resources & Gain employment itself & Professional talent, Multi-cultural workforce \\
Environment & Urbanization, enhancing city image & Pollution, carrying capacity and sustainable planning \\
Culture & Diverse culture & Cultural conflict, cultural distortion \\
\hline
\end{tabular}

This research demonstrated different viewpoints from $B \& R$ as well as how respondents perceived the development in Xinjiang (see Table 2).

From a financial perspective, residents from the rural area expect their household income to be attainable, whereas residents prefer economic benefit, including equal distribution in the resources and government's provision of 
support in small- and medium-sized companies while providing other trade business with other countries across the Silk Road.

In a human resources perspective, residents from the rural area expect to obtain employment and stable jobs, whereas residents in the city prefer other talents and professional people to be brought from B\&R.

For the environmental issues, rural residents prefer urbanization. They wish that the city image can be enhanced to gain possible competitiveness with other cities in China. Conversely, residents from the cities are concerned with pollution, overloaded carrying capacity and thus prefer sustainable and careful planning in Xinjiang.

For the cultural aspect, residents from the rural area prefer cultural diversity, whereas others worry over cultural conflicts and resources shift to the Han Chinese and cultural distortion.

To conclude, the rural residents who support the BRI are mainly seeking personal economic benefits, whereas residents in the city are concerned with other environmental problems and cultural conflicts. Tourism development should be viewed to support economic benefits to the community on condition that it does not degrade their quality of life.

A significant finding in this research suggests that both rural and urban samples identify the effect from cultural issues. Some of the interviewees worry that their culture will be distorted and the resources given to other groups, particularly in small ethnic groups found in Xinjiang. This study provides insights for readers in terms of tourism development probably not limited to economic effects. Cultural issues are also required to take into consideration.

\subsection{Implications for Marketers}

Our results proved that BRI meets the general acceptance from the majority of Xinjiang local residents. Such circumstance provides an opportunity to inform the world regarding Xinjiang and popularise its unique label to the world. Tourism development will also provide additional jobs and an impetus for industry transformation. This circumstance would increase pollution and cause resources drain. However, the following issues must be handled appropriately to maintain a sustainable tourism development.

\subsubsection{Perspective of Tourism Planning and Development}

Xinjiang is located in the middle of the Eurasian continent, with its main nationalities to include Uyghur, Kazakh, Hui, Mongolian, Krgyz, Xibo, Tajik, Uzbek, Manchu, Daur, Tatar, Russian and other ethnic people. Xinjiang is not only the intersection of three major religions, including Islam, Christianity and Buddhism. It is a multi-language region covered by Indo-European, Sino-Tibetan and Altaic languages. Therefore, whether to protect and promote the ethnic and regional tourism resources are vital questions.

The government should take the lead in understanding the Xinjiang tourism translation management, and the Tourism Bureau should begin regulating the correspondence management system. To carry out a timely and comprehensive investigation on tourism translation in Xinjiang, the government should have a practical command over the actual situation in tourism translation and provide basis and support for establishing the system.

Cultural issues are still a significant concern. Officials and planners should carefully address and set up procedures to assess the process of allocating the community via developing tourism while respecting various cultures in the community.

Moreover, environmental and sustainable development requires extra attention. While tourism is planned, developed and managed, the process should ensure that not only its natural and cultural resources will not be depleted or degraded, but maintained as viable resources on a permanent basis for continuous future use. Adopting an acceptable a carrying capacity is an important technique used in the environmental and sustainable development approach.

\subsubsection{Envisioning the Quality of Life of Local Residents}

From the local residents' perspective, the majority of residents are concerned with the effect on their quality of life and economic benefits. Most respondents, particularly those from the city area, considered environmental protection and the exploration of sustainable development. Besides, some locals residents claimed that to narrow down the disparities between the east and west in terms of economic interaction and cultural exchange.

Infrastructure development is a crucial element of the BRI. Nonetheless, this initiative is significantly comprehensive in scope, covering policy dialogue, infrastructure connectivity, unimpeded trade, financial support and people-to-people exchange. Therefore, residents expect economic benefit to support the tourism benefits. However, the destination management should engage with careful planning because the local residents did not want to degrade their environment, subsequently to their quality of life; otherwise, they would view the initiative 
as a negative effect upon the home place and will consequently not support the initiative of $B \& R$ projects.

\subsection{Implications for Academia}

The study had highlighted the findings with identifying the reaction of local residents towards the Xinjiang tourism development under the BRI. Unlike previous studies in which little information regarding the residents were gathered to compare rural and urban areas, the present study highlighted the different viewpoints, thereby encouraging academia to pay further attention on the two groups. Future research can provide with detailing a road map in the study. While providing knowledge to the academia regarding the regional construction planning, planners should further distinguish the improvement of the actual environments in the community using two different group perspectives.

\section{Limitations and Recommendations for Future Study}

Initially, this research contains a small sample size due to time restrictions. This study is limited to Urumqi residents and their opinions, and the results may not be representing all Xinjiang residents in different countries or cities. Therefore, future study should utilise other research methods to collect data, such as quantitative and qualitative methods. The sample size should also be increased and the travel habits of the respondents understood further to deem the findings representative and comprehensive. Furthermore, this study focuses on the tourism development in the vicinity of Urumqi and fails to include other regions in Xinjiang during the different periods. The results may not be comprehensive. Future studies should increase the number of respondents in the interviews, and these respondents must be residents from the other areas in Xinjiang to verify the expectations of the residents towards BRI.

\section{References}

Allen, L. R., Hafer, H. R., Long, P. T., \& Perdue, R. R. (1993). Rural Residents' attitudes toward recreation and tourism development. Journal of Travel Research, 27-33. https://doi.org/10.1177/004728759303100405

Ali, H., Sedigheh, M., \& Amran, H. (2016). The impact of emotional solidarity on residents' attitude and Tourism Development. PLos One, 11(6), 1-14.

Andereck, K. L., Valentine, K. M., Knopf, R. C., \& Vogt, C. A. (2005). Residents' perceptions of community tourism impacts. Annals of Tourism Research, 32(4), 1056-1076. https://doi.org/10.1016/j.annals.2005.03.001

Andriotis, K., \& Vaughan, R. (2003). Urban residents' attitudes toward tourism development; the case of Crete. Journal of Travel Research, 4(2), 172-185. https://doi.org/10.1177/0047287503257488

Asian Development Bank and Asian Development Bank Institute. (2009). Infrastructure for a Seamless Asia, Manila and Tokyo.

Ap, J. (1992). Residents' perception on tourism impact. Annals of Tourism Research, 19(4), 665-690. https://doi.org/10.1016/0160-7383(92)90060-3

Bimonte, S., \& Faralla, V. (2014). Happiness and nature-based vacations. Annals of Tourism Research, 46, 176-178. https://doi.org/10.1016/j.annals.2014.02.002

Belt and Road information. (2009). Infrastructure for a seamless Asia, Manila and Tokyo. Asian Development Bank and Asian Development Bank Institute. Retrieved from https://www.adb.org/documents/adb-annual-report-2009 on Nov 182016

Boley, B. B., Mcgehee, N. G., Perdue, R. R., \& Long, P. (2014). Empowerment and resident attitudes toward tourism: Strengthening the theoretical foundation through a weberian lens. Annals of Tourism Research, 49, 33-50. https://doi.org/10.1016/j.annals.2014.08.005

Chen, Z., Li, L., \& Li, T. (2013). The organizational evolution, systematic construction and empowerment significance of Langde Miao's community tourism. Tourism Tribune, 28(6), 75-86.

China sets up leading team on Belt and Road initiative. (2015). Retrieved from http://news.xinhuanet.com/english/2015-03/29/c_134107435.htm

Choi, H. C., \& Sirakaya, E. (2006). Sustainability indicators for managing community tourism. Tourism Management, 27(6), 1274-1289. https://doi.org/10.1016/j.tourman.2005.05.018

Cropanzano, R., \& Mitchell, M. S. (2005). Social exchange theory: An interdisciplinary review. Journal of Management, 31(6), 874-900. https://doi.org/10.1177/0149206305279602

Durkheim, E. (1995). The elementary forms of religious life. New York: Free Press. 
Emerson, R. M. (1996). Social exchange theory. Annual Review of Sociology, 2(1), 335-362. https://doi.org/10.1146/annurev.so.02.080176.002003

Fredline, E., \& Faulkner, B. (2000). Host community reactions; A cluster analysis. Annals of Tourism Research, 27(3), 763-784. https://doi.org/10.1016/S0160-7383(99)00103-6

Global Times. (2015). The One Belt and One Road is very different from the Marshall Plan.

Gursoy, D., Jurowski, C., \& Uysal, M. (2002). Residents attitudes: A structural modeling approach. Annual of Tourism Research, 29(1), 79-105. https://doi.org/10.1016/S0160-7383(01)00028-7

Huang, Y. P. (2016). Understanding China's Belt \& Road Initiative: Motivation, framework and assessment. China Economic Review, 40, 314-321. https://doi.org/10.1016/j.chieco.2016.07.007

Haobin Ye, B., Qin Zhang, H., Huawn, S., \& Goh, C. (2014). Does social identity affect residents' attitudes toward tourism development? An evidence from the relaxation of the individual visit scheme. International Journal of Contemporary Hospitality Management, 26(6), 907-929. https://doi.org/10.1108/IJCHM-01-2013-0041

Hua, Y. (2015). The time is just right for comprehensively advancing One Belt One Road. Retrieved from http://www.bjreview.com.cn/quotes/txt/2015-03/14/content_678299.htm

Jiang, Z. (2015). ASEAN will gain from Maritime Silk Road, China Daily. Retrieved from http://www.usa.chinadaily.com.cn/opinion/2015-03/31/content_19957721.htm

Jurowski, C., Uysal, M., \& William, D. R. (1997). A theoretical analysis of host community residents' reaction to tourism. Journal of Travel Research, 36(2), 3-11. https://doi.org/10.1177/004728759703600202

Kim, K., Uysal, M., \& Sirgy, M. J. (2013). How does tourism in a community impact the quality of life of community residents? Tourism Management, 36, 527-540. https://doi.org/10.1016/j.tourman.2012.09.005

Ko, D., \& Stewart, W. P. (2002). A structural equation model of residents' attitudes for tourism development. Tourism Management, 46, 465-476. https://doi.org/10.1016/S0261-5177(02)00006-7

Korca, P. (1998). Resident perceptions of tourism in a resort town. Leisure Sciences, 20(3), 193-212. https://doi.org/10.1080/01490409809512280

Lim, Y. L. (2017). Zhejiang sees Singapore as base for Belt and Road ventures into South-east Asia. The Straits Times.

Retrieved

from

http://www.straitstimes.com/asia/east-asia/zhejiang-sees-singapore-as-base-for-belt-and-road-ventures-intosouth-east-asia

Liu, J. C., \& Var, T. (1986). Resident attitudes toward tourism impact in Hawaii. Annals of Tourism Research, 13(2), 193-214. https://doi.org/10.1016/0160-7383(86)90037-X

Madrigal, R. (1995). Residents' perceptions and the role of the government. Annals of Tourism Research, 22(1), 86-102. https://doi.org/10.1016/0160-7383(94)00070-9

McCool, S. F., \& Martin, S. R. (1994). Community attachment and attitudes towards tourism development, Journal of Travel Research, 32(3), 29-34. https://doi.org/10.1177/004728759403200305

Megehee, N., \& Andereck, K. (2004). Factors predicting rural residents' support of tourism. Journal of Travel Research, 43(2), 188-200. https://doi.org/10.1177/0047287504268234

Miles, M. B., \& Huber man, A. M. (1994). Qualitative data analysis. London: SAGE Publications.

Morrison, A. (2009). Hospitality and travel marketing (4th ed.). Albany, NY: Delmar Thomson Learning.

Nawijin, J. (2011). Determinants of daily happiness on vacation. Journal of Travel Research, 50(5), 559-566. https://doi.org/10.1177/0047287510379164

Nawijin, J., \& Mitas, O. (2012). Resident attitudes to tourism and their effect on subjective well-being: the case of Palma de Mallorca. Journal of Travel Research, 51(5), 531-541. https://doi.org/10.1177/0047287511426482

Nicholas, L. N., Thapa, B., \& Ko, Y. J. (2009). Residents' perspectives of a world heritage site, The pitons management area. Annals of Tourism Research, 36(3), 390-412. https://doi.org/10.1016/j.annals.2009.03.005

Permal, S. (2017). China's one belt, one road initiative; Strengthening economic linkages for mutual benefit. Straits Times. Retrieved from https://www.nst.com.my/opinion/columnists/2017/05/235414/chinas-one-belt-one-road-initiative-strengthen ing-economic

Rasoolimanesh, S. M., Jaafar, M., Kock, N., \& Ramayah, T. (2015). A revised framework of social exchange 
theory to investigate the factors influencing residents' perceptions. Tourism Management Perspectives, 16, 335-345. https://doi.org/10.1016/j.tmp.2015.10.001

Rayila, M. (2011). The pain of a Nation: The invisibility of Uyghurs in China Proper. The Equal Rights Review, Six, 44-57.

Robin, N. (2016). Toward a more comprehensive use of social exchange theory to study residents' attitudes to tourism. Procedia Economics and Finance, 39, 588-596. https://doi.org/10.1016/S2212-5671(16)30303-3

Sharpley, R. (2014). Host Perceptions of tourism: A review of research. Tourism Management, 42, 37-49. https://doi.org/10.1016/j.tourman.2013.10.007

Simmons, D. G. (1994). Community participation in tourism planning. Tourism Management, 15(2), 98-108. https://doi.org/10.1016/0261-5177(94)90003-5

Sutton, Jr. W. (1967). Travel and understanding: Notes of the social structure of tourism. Journal of Comparative Sociology, 8, 217-223. https://doi.org/10.1177/002071526700800206

Swaine, M. D. (2014). Chinese Views and Commentary on the "One Belt, One Road” Initiative. China Leadership Monitor. $\quad$ Retrieved from http://www.hoover.org/research/chinese-views-and-commentary-periphery-diplomacy

Uysal, M. et al. (2013). Handbook of tourism and quality of life research: Enhancing the lives of tourist and residents of host communities. London, UK: Springer.

Wang, Y. A., \& Pfister, R. E. (2008). Residents attitudes toward tourism and perceived personal benefits in a rural community. Journal of Travel Research, 47(1), 84-93. https://doi.org/10.1177/0047287507312402

Woosam, K. M., Norman, W. C., \& Ying, T. (2009). Exploring the theoretical framework of emotional solidarity between residents and tourist. Journal of Travel Research, 48(2), 245-258. https://doi.org/10.1177/0047287509332334

Woosam, K. M. (2012). Using emotional solidarity to explain residents' attitudes about tourism and tourism development. Journal of Travel Research, 51(3), 315-327. https://doi.org/10.1177/0047287511410351

Wu, H. X. (2014). Rethinking China's industrialization: Economic explanation of roles of the state and government, 75, 1-23.

Wu, J. M. (2017). One Belt and One Road, Far-reaching Initiative. China-US Focus China Daily. Retrieved from ttp://usa.chinadaily.com.cn/opinion/2017

Xinjiang census. (2010). China Policy Analysis. Retrieved from https:/cpianalysis.org/2016/03/07/spatial-results-of-the-2010-census-in-xinjiang/

Economic Watch: Economic development in Xinjiang on fast lane. (2017). Xinhuanet. Retrieved from http://news.xinhuanet.com/english/2017-07/11/c_136435987.htm

Xinjiang Population. (2016). Beijing Review. Retrieved from http:/www.bjreview.com/Nation/201606/t20160608_800059009.html

Yuksel, F., Bramwell, B., \& Yuksel, A. (1999). Stakeholder interviews and tourism planning at Pamukkale, Turkey. Tourism Management, 20(3), 351-360. https://doi.org/10.1016/S0261-5177(98)00117-4

Zhou, Y., \& Ap, J. (2009). Residents' perceptions towards the impacts of the Beijing 2008 Olympic games. Journal of Travel Research, 48(1), 78-91. https://doi.org/10.1177/0047287508328792

\section{Copyrights}

Copyright for this article is retained by the author(s), with first publication rights granted to the journal.

This is an open-access article distributed under the terms and conditions of the Creative Commons Attribution license (http://creativecommons.org/licenses/by/4.0/). 